Proceedings

\title{
Synthesis of a Novel Series of Phosphonate- Functionalized 1,2,3-Triazoles as Potential Candidates for Allosteric Modulation of $\alpha 7$ Nicotinic Acetylcholine Receptors ${ }^{\dagger}$
}

\author{
Santiago A. Stabile ${ }^{1, *}$ and Cristian Vitale ${ }^{2}$ \\ 1 Instituto de Química del Sur (INQUISUR-CONICET), Depto. de Química, Universidad Nacional del Sur, \\ Av. Alem 1253, B8000CPB Bahía Blanca, Argentina \\ 2 Depto. de Química, Universidad Nacional del Sur, Av. Alem 1253, B8000CPB Bahía Blanca, Argentina; \\ cvitale@criba.edu.ar \\ * Correspondence: Santiago.stabile@uns.edu.ar \\ + Presented at the 22nd International Electronic Conference on Synthetic Organic Chemistry, \\ 15 November-15 December 2018; Available Online: https://sciforum.net/conference/ecsoc-22. \\ Published: 14 November 2018
}

\begin{abstract}
Nicotinic acetylcholine receptors (nAChR) are ligand-gated ion channels formed by the assembly of five subunits. Receptor activity could be subjected to both positive and negative modulation at allosteric sites by endogenous neurotransmitters as well as synthetic ligands such as steroids, bivalent cations, alcohols, and a range of drugs. The subtype of $\alpha 7 \mathrm{nAChR}$ has been considered a potential therapeutic target for Alzheimer's disease, schizophrenia and other neurological and psychiatric disorders. In this work we present the synthesis of a novel series of phosphonate-functionalized 1,4-disubstituted 1,2,3-triazoles with potential activity over $\alpha 7$ AChR. These compounds were synthetized through the copper-catalyzed Huisgen 1,3-dipolar cycloaddition of organic azides and alkynes. Copper nanoparticles (CuNPs) immobilized on different supports were prepared using the $\mathrm{CuCl}_{2}$-Li-DTBB reducing system previously reported by our group.
\end{abstract}

Keywords: 1,2,3-triazoles; phosphonates; nicotinic receptors

\section{Introduction}

Nicotinic acetylcholine receptors (nAChRs) are transmembrane receptors that are activated by the neurotransmitter acetylcholine. These receptors are distributed throughout the central and peripheral nervous systems and play important roles in several (patho)physiological processes [1]. Seventeen subunits have been identified in vertebrates $(\alpha 1-10, \beta 1-4, \gamma, \delta$ and $\varepsilon)$, which co-assemble to form a diverse family of receptor subtypes. In particular, the human $7 \mathrm{nAChR}$ has been identified as a potential target for therapeutic drug discovery and has been implicated in a number of neurological and psychiatric disorders [2]. Considering the fact that $\alpha 7 \mathrm{nAChR}$ undergoes very rapid desensitisation in response to agonist activation, several positive allosteric modulators (PAMs) were synthesized and evaluated. $\alpha 7 \mathrm{nACh}$ PAMs are classified in two types: those that do not change the AChR desensitization properties are called type I whereas those that decrease the level of desensitization are labeled as type II.

The identified $\alpha 7$ PAMs have considerable diversity, ranging from proteins to small molecules. Even the small molecule PAMs vary significantly in structure, as well as in properties and probably 
mechanisms of the modulation. Nitrogen-containing heterocycles such as indoles, isoxazoles, thiazoles, pyridines and pyrroles are largely present in both type I and type II PAMs [3].

Frequently, isosteric replacement of this heterocycles, or amide linkers, with triazole rings allows the efficient generation of small libraries of ligands for $\mathrm{nAChR}$ via one-pot copper(I)-catalyzed azidealkyne cycloaddition. In this way, several triazole-containing agonists of $\mathrm{nAChR}$ were synthesized [4]. 1,2,4-triazoles are also present in structures acting over nicotinic receptors. Derivatives of 4BPTQS, a potent allosteric agonist of $\alpha 7 \mathrm{nAChRs,} \mathrm{showed} \mathrm{properties} \mathrm{of} \mathrm{type} \mathrm{I} \mathrm{or} \mathrm{II} \mathrm{PAMs} \mathrm{[5].}$

Our group developed methodologies to synthesize triazoles. Copper nanoparticles (CuNPs) can be obtained through the reducing system $\mathrm{CuCl}_{2} \cdot 2 \mathrm{H}_{2} \mathrm{O}$, lithium metal, and a catalytic amount of 4,4'di-tert-butylbiphenyl (DTBB) in tetrahydrofuran (THF) at room temperature. We showed that these unsupported copper nanoparticles (10 mol\%) effectively catalysed the 1,3-dipolar cycloaddition of organic azides and terminal alkynes in the presence of triethylamine at $65^{\circ} \mathrm{C}$ in THF. Moreover, these CuNPs can be supported over activated carbon and perform the multicomponent synthesis of 1,2,3triazoles from organic halides in water, allowing the recycling and reuse of the catalyst [6].

In the other hand phosphonates and related compounds exhibit a wide range of applications in medicinal chemistry. For example, some of these compounds are potent inhibitors of human acetylcholinesterase [7]. Thus, in this work we present the synthesis of a novel series of phosphonatefunctionalized 1,4-disubstituted 1,2,3-triazoles.

\section{Materials and Methods}

\subsection{Synthetic Procedures}

Reagents employed were analytical grade. THF and $\mathrm{CH}_{2} \mathrm{Cl}_{2}$ were freshly distilled over sodium/benzophenone or $\mathrm{CaH}_{2}$ respectively. Moisture-sensitive reactions were conducted under inert atmosphere of dry nitrogen using oven dried glassware. Reactions were monitored by analytical thin layer chromatography (TLC) performed on Merck silica gel 60 F254 plates and visualized under ultraviolet (UV) light and/or using phosphomolybdic acid or p-anisaldehyde solutions. Purification of crude materials was performed by flash chromatography on silica gel (200-400 mesh, Merck).

\subsection{General Procedure for Azide-Alkyne Cycloaddition Employing CuNPs/C in Water}

$\mathrm{NaN}_{3}$ (1.2 eq.), the organic halide ( 1 eq.), and the alkyne (1 eq.) were added to a suspension of $\mathrm{CuNPs} / \mathrm{C}(5 \mathrm{~mol} \% \mathrm{Cu})$ in $\mathrm{H}_{2} \mathrm{O}$. The reaction mixture was warmed to $70{ }^{\circ} \mathrm{C}$ overnight. Then, the mixture was diluted with water and extracted with EtOAc. The collected organic phases were dried with anhydrous $\mathrm{Na}_{2} \mathrm{SO}_{4}$, dried and purified by flash chromatography.

\subsection{General Procedure for Azide-Alkyne Cycloaddition Employing CuNPs/C in THF}

Organic azide ( 1 eq.), alkyne (1 eq.) and triethyl amine (1 eq.) were added to a suspension of $\mathrm{CuNPs} / \mathrm{C}(5 \mathrm{~mol} \% \mathrm{Cu})$ in THF. The reaction mixture was heated under reflux overnight. Then, THF was removed and the mixture was washed with water, followed by extractions with EtOAc. The collected organic phases were dried with anhydrous $\mathrm{Na}_{2} \mathrm{SO}_{4}$, dried, and purified by flash chromatography.

\section{Results and Discussion}

The 1,4-disubstitued triazole derivatives synthesized in this work are shown in Figure 1. We have successively synthesized two series of derivatives, taking into account the preliminary results in their evaluation as $\alpha 7 \mathrm{nAChRs}$ PAMs. In the first series, structure activity relationship strategies (SAR) were employed and we observed that compounds bearing a phosphonate moiety presented the desired activity. Thus, we continued synthesizing phosphonate derivatives in order to enhance the activity. 
SERIES I<smiles>OCc1cn(Cc2cccc3ccccc23)nn1</smiles><smiles>BrCc1cn(Cc2cccc3ccccc23)nn1</smiles><smiles>[R20]Cc1cn(Cc2cccc3ccccc23)nn1</smiles><smiles>O=POCc1cn(Cc2cccc3ccccc23)nn1</smiles>

SERIES II<smiles>COCCc1cn(Cc2cccc3ccccc23)nn1</smiles><smiles>COc1cn(-c2cccc3ccccc23)nn1</smiles><smiles>COCn1cc(Cc2cccc3ccccc23)nn1</smiles>

Figure 1. 1,4-disubstituted-1,2,3-triazoles synthesized in this work.

\subsection{Synthesis of 1,2,3-Triazoles Using Supported Copper Nanoparticles}

We found that CuNPs supported over activated carbon were able to promote the 1,3-dipolar cycloaddition between 1-azidometylnaphtalene, formed from the corresponding chloride in the reaction media, and propargyl alcohol in water at $70{ }^{\circ} \mathrm{C}$. Afterwards, as shown in Scheme 1 , compound 1 was transformed in the corresponding bromide, which was subjected to the MichaelisBecker reaction with different hydrogen phosphonates, obtaining dialkyl phosphonates esters 3a-c. Finally, phosphonic acid 4 was obtained through the hydrolysis of compound $3 a$ in the presence of trymethyl sylil bromide (TMSBr).

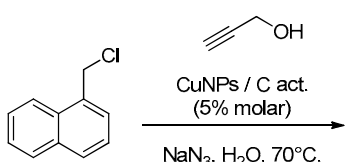

$82 \%$

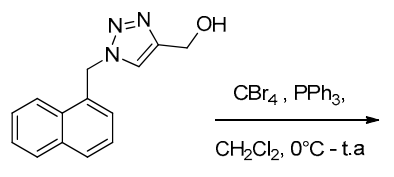

1

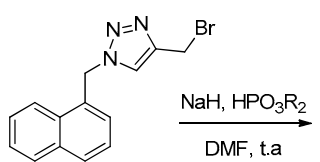

2

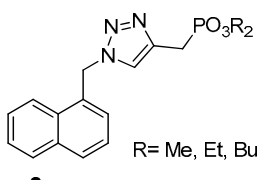

3 a-c<smiles>COc1cn(Cc2cccc3ccccc23)nn1</smiles>

Scheme 1. Synthesis of 1,4-disubstituted 1,2,3-triazole series I.

\subsection{Structure Activity Relationship (SAR) Studies. Synthesis of Homologs of Phosphonate-Triazoles and} Invertion of Triazole Geometry

Considering that in preliminary studies of the first series of compounds dimethyl phosphonate ester 3a exerted higher activity as $\alpha 7 \mathrm{nAChRs}$ PAM, we decided to synthesize homologs of this compound. We made variations in the distances between the groups' naphthalene-triazole and phosphonate-triazole, leading to derivatives $\mathbf{5}$ and $\mathbf{6}$. In both cases $\mathrm{CuNPs} / \mathrm{C}$ were used as catalyst for the cycloaddition reaction. 1-azidonaphtalene was obtained via diazonium salt in excellent yields. In this case, dimethyl phosphonates esters were obtained via the Arbuzov reaction with higher yields than the former method. 

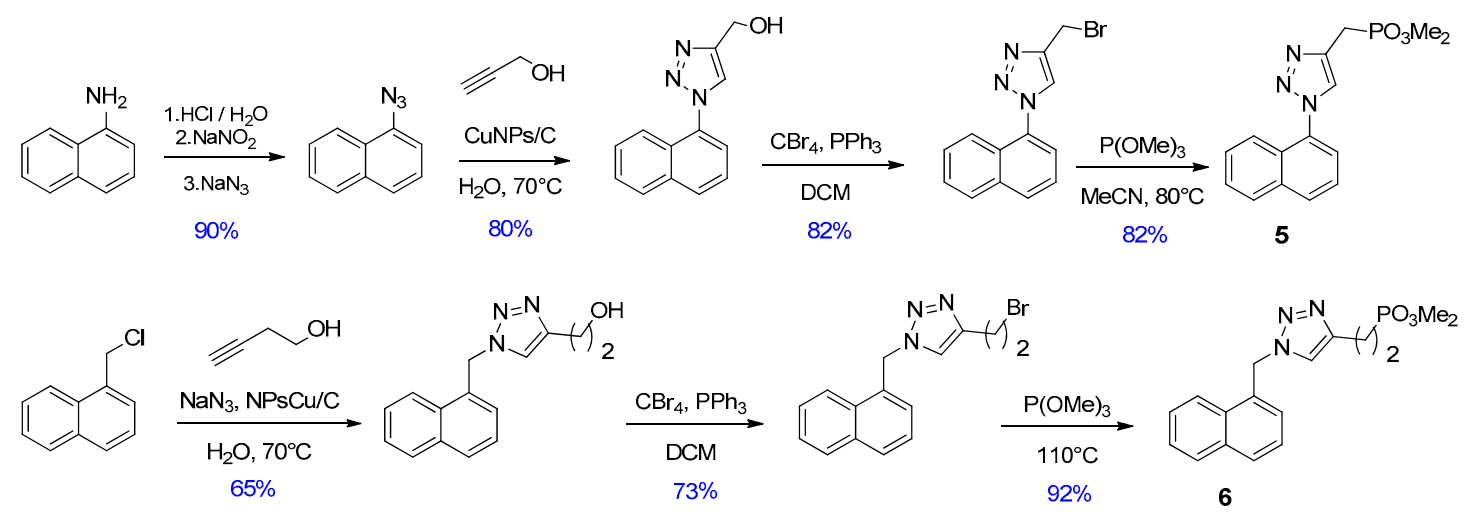

Scheme 2. Synthesis of 1,2,3-triazole series II.

On the other hand, we put our efforts into the synthesis of an analogue of phosphonate 3a with the inversion of triazole geometry, i.e., with phosphonate ester functionality contained in the organic azide. Retrosynthetic analysis is shown in Figure 2. It is noteworthy that this approach is more convergent that that used for the synthesis of the previous phosphonates, this is because we were unable to obtain the corresponding propargylic phosphonate through substitution of propargylic bromide with phosphite esters.

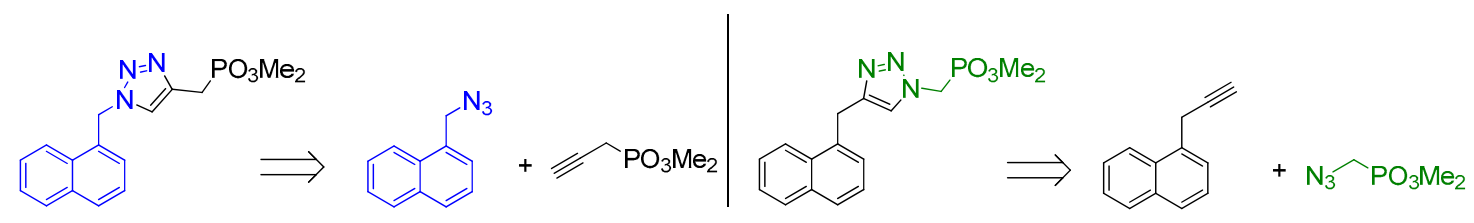

Figure 2. Retrosynthetic analysis of triazole inverted dimethyl phosphonate ester.

Azidomethyl dimethyl phosphonate was synthesized from the corresponding hydroxymethyl phosphonate, which in turn was obtained by the reaction of dimethyl phosphite with paraformaldehyde, in the presence of a mild base [8]. It is worthy of mention that it is essential to use triflates to obtain the azidomethyl phosphonate in good yield, considering the low reactivity of 1(mesyloxy) or 1-(tosyloxy)alkyl phosphonates and the fact that an increase in temperature could produce mono-dealkylation reactions in both substrate and product [9]. For the synthesis of the desired alkyne, we employed a modification of the coupling reaction between benzyl halides and terminal alkynes promoted by $\mathrm{CuI}$ as described by Wulff and coworkers [10]. Once again, the copper catalyzed azide-alkyne cycloaddition was successfully performed with CuNPs/C. 


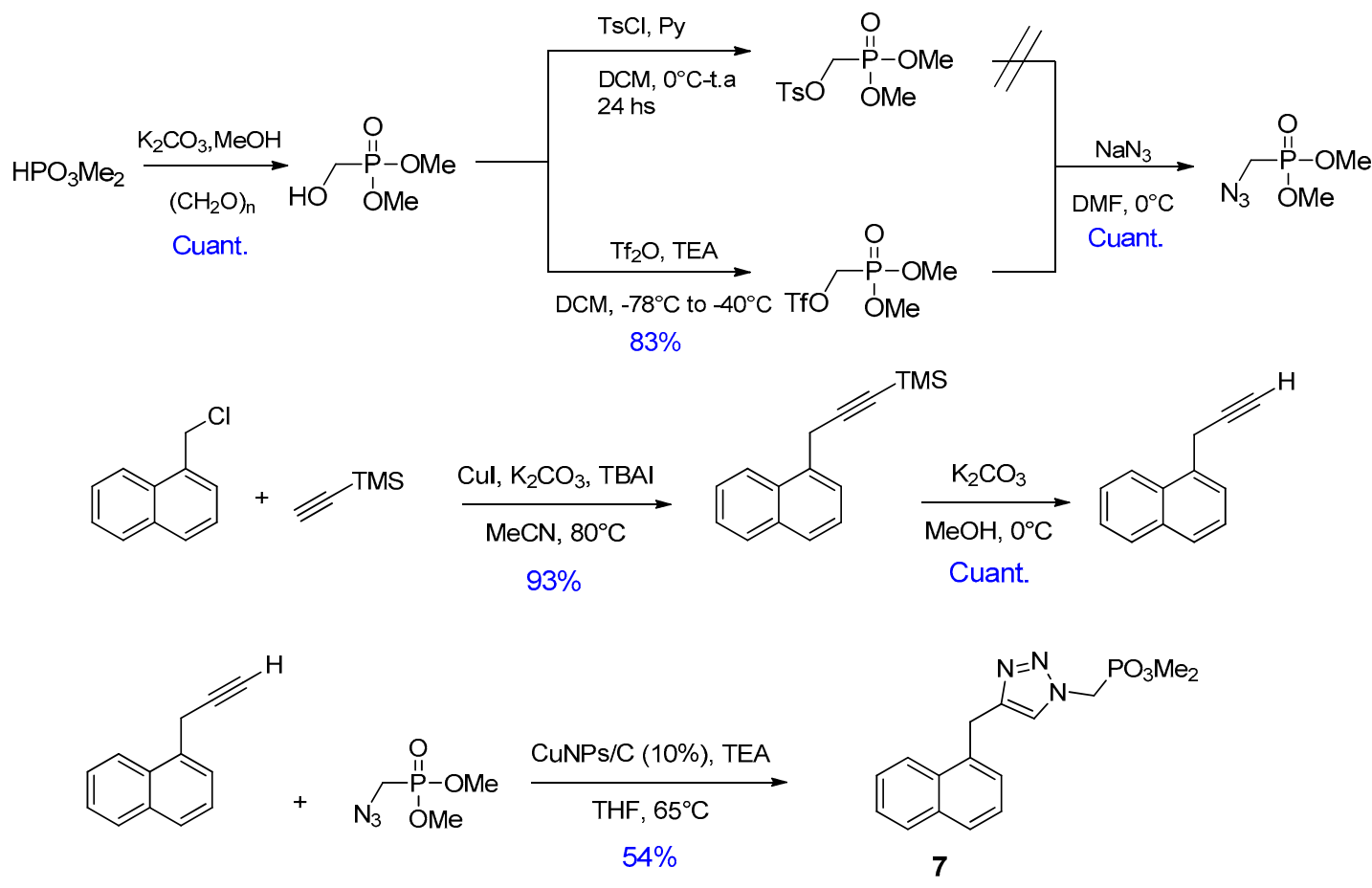

Scheme 3. Synthesis of the target compound 7.

\section{Conclusions}

The synthesis of a novel series of phosphonate-functionalized 1,4-disubstituted 1,2,3-triazoles was achieved through the methodologies developed by our group, consisting in the preparation of copper-based catalysts in the form of supported nanoparticles. Preliminary studies on their activity as $\alpha 7 \mathrm{nAChR}$ PAMs show that those with phosphonate functionality, especially dimethyl phosphonate esters, present the desired activity.

Funding: This work was supported by the Agencia Nacional de Promoción Científica y Tecnológica (ANPCyT, Prest. BID PICT 2014-2171), Secretaria General de Ciencia y Técnica de la Universidad Nacional del Sur (PGI24/Q072), and the Consejo Nacional de Investigaciones Científicas y Técnicas (CONICET, PIP-2014-498).

Conflicts of Interest: The authors declare no conflict of interest.

\section{References}

1. Garai, S.; Krishnamohan S.R. B-973-A Novel 7 nAChR Ago-PAM: Racemic and Asymmetric Synthesis, Electrophysiological Studies and in vivo Evaluation. ACS Med. Chem. Lett. 2018, 9, 1144-1148, doi:10.1021/acsmedchemlett.8b00407.

2. Broad, L.M.; Zwart, R. Identification and Pharmacological Profile of a New Class of Selective Nicotinic Acetylcholine Receptor Potentiators. J. Pharmacol. Exp. Ther. 2006, 318, 1108-1117, doi:10.1124/jpet.106.104505.

3. Williams, D.K.; Wang, J. Positive allosteric modulators as an approach to nicotinic acetylcholine receptortargeted therapeutics: Advantages and limitations. Biochem. Pharmacol. 2011, 82, 915-930, doi:10.1016/j.bcp.2011.05.001.

4. Rizzi, L.; Gotti, C. A Small Library of 1,2,3-Triazole Analogs of CAP-55: Synthesis and Binding Affinity at Nicotinic Acetylcholine Receptors. Chem. Biodivers. 2018, 15, e1800210, doi:10.1002/cbdv.201800210.

5. Chatzidaki, A.; D'Oyley, J.M. The influence of allosteric modulators and transmembrane mutations on desensitisation and activation of a7 nicotinic acetylcholine receptors. Neuropharmacology 2015, 97, 75-85, doi:10.1016/j.neuropharm.2015.05.006.

6. Alonso, F.; Moglie, F. Copper Nanoparticles in Click Chemistry. Acc. Chem. Res. 2015, 48, 2516-2528, doi:10.1021/acs.accounts.5b00293. 
7. Timperley, C.M. Phosphonyl Compounds. In Best Synthetic Methods: Organophosphorus (V) Chemistry; Academic Press: London, UK, 2013; pp. 91-325, ISBN 978-0-08-098212-0.

8. Jeanmaire, T.; Hervaud, Y. Synthesis of Dialkyl-Hydroxymethylphosphonates in Heterogeneous Conditions. Phosphorus Sulfur Silicon Relat. Elem. 2012, 177, 1137-1145, doi:10.1080/10426500211718.

9. Błaszczyk, R.; Gajda, T. Convenient Synthesis of Dialkyl 1-Azidoalkylphosphonates using Tetramethylguanidinium Azide as Azidation Agent. Synth. Commun. 2008, 38, 1110-1119, doi:10.1080/00397910701863483.

10. Davies, K.A.; Abel, R.C. Operationally Simple Copper-Promoted Coupling of Terminal Alkynes with Benzyl Halides. J. Org. Chem. 2009, 74, 3997-4000, doi:10.1021/jo900444x.

(C) 2019 by the authors. Licensee MDPI, Basel, Switzerland. This article is an open access article distributed under the terms and conditions of the Creative Commons Attribution (CC BY) license (http://creativecommons.org/licenses/by/4.0/). 